\title{
The clearwater consensus: the estimation of metal hazard in fresh water
}

\author{
Miriam L. Diamond • Nilima Gandhi • William J. Adams • John Atherton • \\ Satyendra P. Bhavsar • Cécile Bulle • Peter G. C. Campbell • Alain Dubreuil • \\ Anne Fairbrother • Kevin Farley • Andrew Green • Jeroen Guinee • \\ Michael Z. Hauschild • Mark A. J. Huijbregts • Sébastien Humbert • Karen S. Jensen • \\ Olivier Jolliet • Manuele Margni • James C. McGeer • Willie J. G. M. Peijnenburg • \\ Ralph Rosenbaum • Dik van de Meent • Martina G. Vijver
}

Received: 27 November 2009 / Accepted: 28 November 2009/Published online: 8 January 2010

(C) The Author(s) 2009. This article is published with open access at Springerlink.com

\begin{abstract}
Background, aim, and scope Task Force 3 of the UNEP/ SETAC Life Cycle Initiative has been working towards developing scientifically sound methods for quantifying impacts of substances released into the environment. The Clearwater Consensus follows from the Lausanne (Jolliet et al. Int J Life Cycle Assess 11:209-212, 2006) and Apeldoorn (Apeldoorn Int J Life Cycle Assess 9(5):334, 2004) statements
\end{abstract}

\footnotetext{
M. L. Diamond ( $\triangle)$

Department of Geography, University of Toronto,

100 St. George Street,

Toronto, ON M5S 3G3, Canada

e-mail: miriam.diamond@utoronto.ca

N. Gandhi

Department of Chemical Engineering, University of Toronto,

100 St. George Street,

Toronto, ON M5S 3G3, Canada

\section{W. J. Adams}

Rio Tinto,

7760 N. Boulder Drive,

Lakepoint, UT 84074, USA

\section{J. Atherton}

ICMM 35/38 Portman Square,

London W1H 6LR, UK

S. P. Bhavsar

Ontario Ministry of the Environment,

125 Resources Road,

Etobicoke, ON M9P 3V6, Canada

C. Bulle $\cdot$ M. Margni $\cdot$ R. Rosenbaum

Ecole Polytechnique de Montréal, 2900 Edouard-montpetit,

P.O. Box 6079, Stn. Centre-ville,

Montreal, QU H3C 3A7, Canada
}

by recommending an approach to and identifying further research for quantifying comparative toxicity potentials (CTPs) for ecotoxicological impacts to freshwater receptors from nonferrous metals. The Clearwater Consensus describes stages and considerations for calculating CTPs that address inconsistencies in assumptions and approaches for organic substances and nonferrous metals by focusing on quantifying the bioavailable fraction of a substance.

\section{P. G. C. Campbell}

Institute National de la Recherché Scientifique,

490 rue de la Couronne,

Québec, QU G1K 9A9, Canada

A. Dubreuil

Mining and Mineral Sciences Labs, CANMET,

555 Booth Street,

Ottawa, ON K1A 0G1, Canada

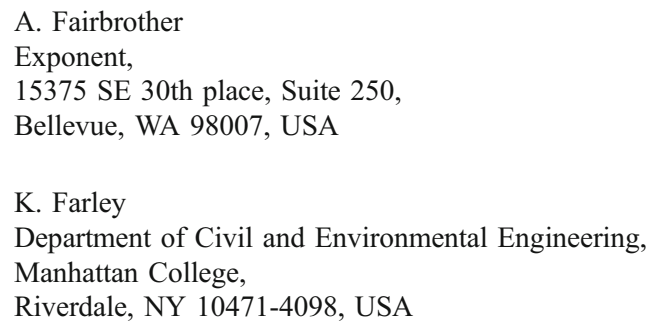

A. Green

International Zinc Association,

1822 E NC Highway 54, Suite 120,

Durham, NC 27713, USA

J. Guinee $\cdot$ M. G. Vijver

Institute of Environmental Sciences, University of Leiden, P.O. Box 9518, 2300 RA Leiden, The Netherlands 
Methods A group of specialists in Life Cycle Assessment, Life Cycle Impact Assessment, metal chemistry, and ecotoxicology met to review advances in research on which to base a consensus on recommended methods to calculate CTPs for metals.

Conclusions and recommendations Consensus was reached on introducing a bioavailability factor (BF) into calculating CTPs where the BF quantifies the fraction of total dissolved chemical that is truly dissolved, assuming that the latter is equivalent to the bioavailable fraction. This approach necessitates calculating the effects factor, based on a $\mathrm{HC} 50_{\mathrm{EC} 50}$, according to the bioavailable fraction of chemical. The Consensus recommended deriving the $\mathrm{BF}$ using a geochemical model, specifically WHAM VI. Consensus was also reached on the need to incorporate into fate calculations the speciation, size fractions, and dissolution rates of metal complexes for the fate factor calculation. Consideration was given to the characteristics of the evaluative environment defined by the multimedia model, which is necessary because of the dependence of metal bioavailability on water chemistry.

Keywords Comparative toxicity potentials $\cdot$ Freshwater ecotoxicity $\cdot$ Life cycle impact assessment $\cdot$ Metal bioavailability . Nonferrous metals

\section{Background, aim, and scope}

A group of specialists in Life Cycle Assessment (LCA), Life Cycle Impact Assessment (LCIA), and metal chemistry and ecotoxicity from academia, industry, and government met in Clearwater, Florida, USA from November 14 to 15, 2008. The meeting was co-sponsored by UNEP/SETAC LCA and International Council on Mining and Metals and had representation from the UNEP/SETAC Life Cycle

M. Z. Hauschild

Technical University of Denmark, DTU-MAN,

Building 424,

280 Lyngby, Denmark

M. A. J. Huijbregts · D. van de Meent

Department of Environmental Science,

Radboud University,

P.O. Box 9010,

6500 Nijmegan, The Netherlands

S. Humbert

Rue Verte,

1261 Le Vaud, Switzerland

\section{K. S. Jensen}

Department of Basic Science and Environment,

University of Copenhagen,

Thorvaldsensvej 40,

1871 Frederiksberg C, Denmark
Initiative through its LCIA Toxic Impacts Task Force. The goal of the meeting was to recommend a method for developing ecological comparative toxicity potentials (CTPs) for metal substances that would be consistent with the current multimedia based practice of setting ecological CTPs for organic substances within the context of LCIA. The group considered only freshwater ecotoxicity. However, the principles expressed in this Consensus may also be relevant for expressing the ecotoxicological hazard of metals in other environmental media such as coastal waters and terrestrial systems.

The meeting started from the conclusions expressed in the Lausanne review workshop (Jolliet et al. 2006) and the Apeldoorn Declaration (Apeldoorn 2004), which among others stated the need to consider metal-specific properties, speciation, and bioavailability when assessing chemical hazard of metal emissions. This need derives from the intent of LCA to compare products and processes using a unified framework and specifically in LCIA, to compare the hazard of all chemicals on a common scale. Following in the spirit of the Apeldoorn and Lausanne statements, the group agreed that differences between organics and nonferrous metals with respect to the bioavailable form of the chemical result in an inconsistent assessment of hazard. The group reached consensus on changes to current practices used to estimate metal hazard that will bring consistency between methods used to assess and estimate the hazard of organic compounds and metals.

This document is based on the following definitions and assumptions:

- The bioavailable fraction of chemical: "[...] the fraction of the total amount of a chemical present in a specific environmental compartment that, within a given time span, is either available or can be made available for uptake by (micro)organisms from either the direct

O. Jolliet

School of Public Health, University of Michigan,

109 South Observatory,

Ann Arbor, MI 48109, USA

J. C. McGeer

Wilfrid Laurier University,

Waterloo, ON N2L 3C5, Canada

W. J. G. M. Peijnenburg

National Institute for Public Health and the Environment,

P.O. Box 1, 3720BA Bilthoven, A. van Leeuwenhoeklaan 9,

Bilthoven, The Netherlands 
Fig. 1 Fractions of total chemical. For metals, the truly dissolved fraction, which is assumed to be bioavailable, is within the total dissolved fraction. In turn, the fraction of free metal ion (e.g., $\mathrm{Me}^{+2}$ ) is within the truly dissolved fraction

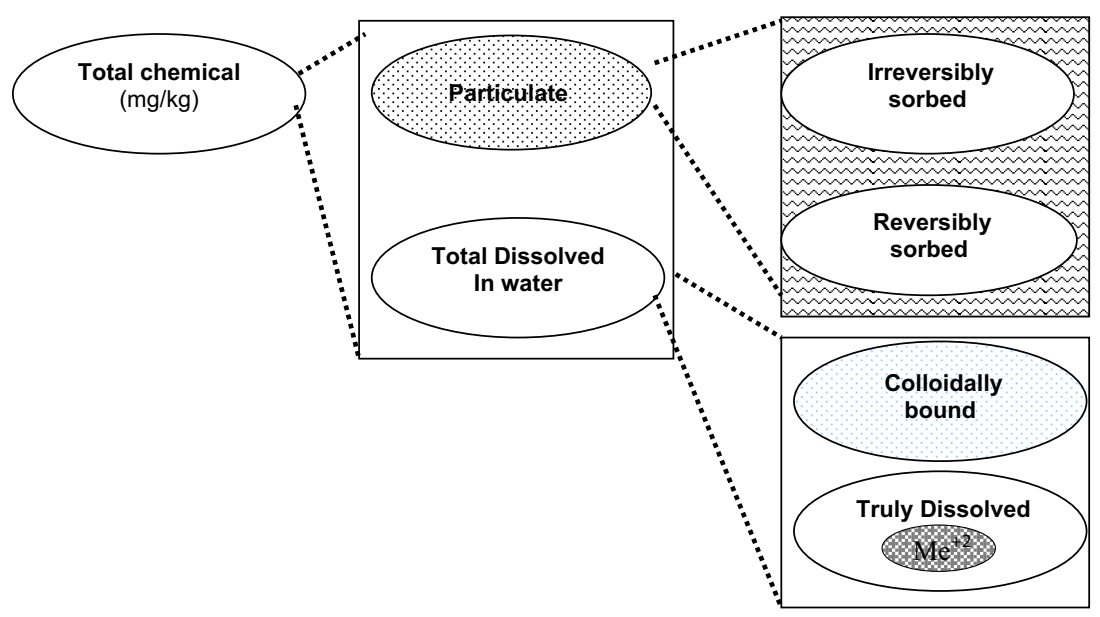

surrounding of the organism [...]" (Peijnenburg and Jager 2003).

- Fractions comprising total chemical: (Fig. 1)

- Total Chemical $=$ Total Dissolved + Particulate

- Total Dissolved $($ or Soluble $)=$ Colloidal + Truly Dissolved

\section{Conclusions and recommendations}

Agreement was reached on the following points:

- Metals in Life Cycle Inventory (LCI)-LCI must account for the species and particle sizes of metals released into the environment. In order to assign appropriate physical-chemical properties in the LCIA phase, so too must the exact species of metal released be known. In addition, for alloys, particle size is relevant because it controls dissolution rates and fate.

- Metal emissions - Current practice assumes that chemicals listed in LCI are available for distribution in an evaluative environment described by a multimedia fate model. Since, except for emissions of soluble metal salts, most particulate forms of metals emitted undergo a slow dissolution process, this assumption is not valid in most cases. We recommend that fate calculations incorporate estimates of dissolution of the emitted species of metal reported in an LCI. How this should be done, particularly which time horizon should be considered for the dissolution process and what influence metal mineralization has on long-term bioavailability, are topics for further research.

- Bioavailability in comparative toxicity potentials $(C T P S)$-Currently, CTPs express the relative hazard of a chemical as the product of a fate factor $(\mathrm{FF})$ and an effects factor $(\mathrm{EF})$ : $\mathrm{CTP}=\mathrm{FF} \times \mathrm{EF}$. CTPs have been developed for the total chemical emitted into the environment (reported by the LCI in "elementary" form). The FF is calculated in terms of total chemical, whereas, the EF is calculated for the total dissolved fraction, which is comprised of a colloidal fraction and the fraction of truly dissolved chemical, which is assumed to be bioavailable (see Fig. 1). Current practice distinguishes between total dissolved (which is often assumed to be truly dissolved) and particulate forms using a particle-to-dissolved partition or distribution coefficient. ${ }^{1}$ This approach assumes that chemical uptake by aquatic organisms is directly from water and does not address dietary uptake.

- Bioavailability Factor (BF): definition-The BF explicitly expresses the relationship between total dissolved and bioavailable chemical where the latter is assumed to be truly dissolved. For metals, BF expresses the truly dissolved (not soluble) fraction of metal. For organics, current practice typically assumes that the total dissolved fraction, including colloidally bound chemical, is bioavailable despite evidence to the contrary (e.g., Haitzer et al. 1998).

- Bioavailability Factor (BF)-The bioavailability factor makes the correction between the total chemical and the truly dissolved fraction that is bioavailable, which for metals can be based on a Biotic Ligand Model (BLM). We recommend that CTP be calculated in terms of the bioavailable fraction of chemical, which for organics and metals, is the truly dissolved fraction and does not include colloidally bound chemical, i.e., CTP $=$ $F F \times B F \times E F$.

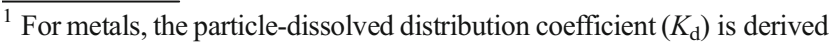
empirically or by using a geochemical model. For organic substances, the organic carbon-water partition coefficient is calculated, often based on the substance's octanol-water partition coefficient, $K_{\mathrm{OW}}$.
} 
- Bioavailability Factor (BF): calculation-A geochemical speciation and complexation model should be used to calculate the BF as the truly dissolved fraction of metal in solution based on inputs of water chemistry (e. g., pH, DOC, total suspended solids or TSS, concentrations of major cations and anions). This geochemical model must be able to consider the binding of metals to natural DOC. Presently, WHAM VI is the most commonly known and used model in this category (Centre for Hydrology and Ecology. Windermere Humic Aqueous Model (WHAM). Natural Environmental Research Council, NERC, Windermere, UK. 2001). CTPs of metals that use BFs for which a robust geochemical calculation is not available should be identified as interim. Further, we recommend that the use of Quantitative Ion Character-Activity Relationships (QICAR) be explored to obtain BFs for metals lacking a robust method of calculation (Ownby and Newman 2003).

- Fate Factor $(F F)$ - FFs for freshwaters may be calculated using the SETAC/UNEP Task Force 3 Consensus Model USEtox (Hauschild et al. 2008; Rosenbaum et al. 2008). The group acknowledges that the consensus model uses a simplified formulation of net sedimentation that presently does not account for sediment-towater diffusive release of soluble metal resulting from post-diagenetic fate processes.

- Effect Factor (EF): metal speciation-EFs for the freshwater ecotoxicity of cations should be calculated based on the metal's truly dissolved fraction, assuming that the free metal ion, which is a fraction within the truly dissolved fraction, is responsible for toxicity. The free metal ion activity should be calculated using a geochemical model. The use of the free metal ion activity is reasonable because of the correspondence between effect concentrations (e.g., EC50) obtained using BLM, which incorporates a geochemical model, and estimates of the Free Metal Ion Activity.

- Effect Factor (EF): toxicity benchmark-EFs should be calculated based on the HC50 $\mathrm{EC5O}_{\mathrm{O}}$, the geometric mean value of EC50s for chronic ecotoxicity tests for multiple freshwater biotic species. The $H C 50_{E C 50}$ is equivalent to the HC50 obtained from a species sensitivity distribution or SSD when the statistical distribution of the SSD is log-normal. In the absence of at least three values of chronic EC50s, the HC5O can be calculated using acute EC50s based on the correspondence between acute and chronic test results. A factor incorporating typical acute-to-chronic ratios should be included in this case.

- Archetypes for freshwaters: the default-The relative value of a metal's CTP depends on ambient chemistry. For freshwaters this effect is most important for bioavailability and toxicity and to a lesser extent, fate. LCA practitioners often do not have information on the location of emission and will therefore require a default value with its corresponding variability range. Metal CTPs should be calculated for one default chemistry (water, $\mathrm{pH}, \mathrm{DOC}$, TSS, and concentrations of major cations and anions) chosen to reflect the "central tendency" of European Union (EU) archetypes and their frequency in emission locations. The European archetypes are well characterized and used within chemical risk assessment. We acknowledge that this central tendency does not reflect the central tendency of freshwaters worldwide (see below). The values of all chemistry parameters should be taken from one archetype determined to be the central tendency, rather than each chemistry parameter independently taken as the central tendency over all archetypes. The variability of a metal's CTP due to the choice of water archetype should be assessed by giving a CTP for this default archetype and the extreme maximum and minimum CTP values obtained for EU archetypes.

- Archetypes for freshwaters: options-CTPs should be calculated for several freshwater archetypes that relate to the frequency of the occurrence of these freshwater chemistries and their relevance in terms of proximity to emissions expressed in the LCI data. Currently, EU water archetypes are available. Future efforts should be directed towards gathering data to characterize global water archetypes. ${ }^{2}$

- Metal concentrations used to calculate CTPS-Metal complexation and speciation and hence, the BF and CTP, vary nonlinearly with background metal concentrations. Background concentrations are highly variable among each metal and geographically at local to global scales (Reinman and Garett 2005). We recommend that as a start, the default archetype and each of the EU archetypes contain background concentrations for each metal. Additional research is recommended to evaluate appropriate metal background concentrations to calculate CTPs.

- Use of internally consistent parameter values-Calculation of each component of the CTP must use consistent parameter values. For example, a consistent value of TSS must be used in USEtox to calculate the $\mathrm{FF}$ and in the geochemical model to calculate $K_{\mathrm{d}}$ and BF. Further consideration may be given to the effect of the archetype-specific value of TSS on the net sedimentation parameter value used in USEtox. However, this consideration should recognize the relative insensi-

\footnotetext{
${ }^{2}$ Determining the relationship between the EU water archetypes and their proximity to emissions (i.e., current LCI databases) is the responsibility of the UNEP/SETAC Task Force 3.
} 
tivity of CTPs to fate parameter values, where CTPs are most sensitive to BF. Another example of the need for consistency is the aerosol settling rate that depends on particle size of emitted metal. The parameters of the default water archetype should be used for determining the CTPs for organic substances to provide for a consistent ranking of CTPs for all substances.

The recommendations contained herein will be implemented under the auspices of the UNEP/SETAC Task Force 3 to obtain CTPs for several common cationic metals.

Open Access This article is distributed under the terms of the Creative Commons Attribution Noncommercial License which permits any noncommercial use, distribution, and reproduction in any medium, provided the original author(s) and source are credited.

\section{References}

Apeldoorn 2004. Ligthart T, Aboussouan L, van de Meent D, Schönnenbeck M, Hauschild M, Delbeke K, Struijs J, Russell A, Udo de Haes H, Atherton J, van Tilborg W, Karman Ch, Korenromp R, Sap G, Baukloh A, Dubreuil A, Adams W, Heijungs R, Jolliet O, de Koning A, Chapman P, Verdonck F, van der Loos R, Eikelboom R, and Kuyper J (2004) Declaration of Apeldoorn on LCIA of Non-Ferrous Metals. Workshop by a group of LCA specialists, held in Apeldoorn, NL, April 15th, 2004. Abstract by Sonnemann G (2004) Int J Life Cycle Assess 9(5):334. Full text available at http://www.leidenuniv.nl/cml/ ssp/projects/declaration_of_apeldoorn.pdf

Haitzer M, Höss S, Traunspurger W, Steinberg C (1998) Effects of dissolved organic matter (DOM) on the bioconcentration of organic chemicals in aquatic organisms - a review. Chemosphere 37:1335-1362

Hauschild MZ, Huijbregts M, Jolliet O, Macleod M, Margni M, van de Meent D, Rosenbaum RK, McKone TE (2008) Building a model based on scientific consensus for Life Cycle Impact Assessment of chemicals: the search for harmony and parsimony. Environ Sci Technol 42:7032-7037

Jolliet O, Rosenbaum R, Chapman PM, McKone T, Margni M, Scheringer M, van Straalen N, Wania F (2006) Establishing a framework for Life Cycle Toxicity Assessment-findings of the Lausanne Review Workshop. Int J Life Cycle Assess 11:209-212

Ownby DR, Newman MC (2003) Advances in quantitative ion character-activity relationships (QICARs): using metal-ligand binding characteristics to predict metal toxicity. QSAR Combinatorial Sci 22(2):241-246

Peijnenburg W, Jager T (2003) Monitoring approaches to assess bioaccessibility and bioavailability of metals: matrix issues. Ecotoxicol Environ Saf 56:63-77

Reinman C, Garett RG (2005) Geochemical background-concept and reality. Sci Total Environ 350(1-3):12-27

Rosenbaum RK, Bachmann TM, Swirsky Gold L, Huijbregts MAJ, Jolliet O, Juraske R, Koehler A, Larsen HF, MacLeod M, Margni M, McKone TE, Payet J, Schuhmacher M, van de Meent D, Hauschild MZ (2008) USEtox - the UNEP/SETAC toxicity model: recommended characterisation factors for human toxicity and freshwater ecotoxicity in life cycle impact assessment. Int J Life Cycle Assess 13:532-546 